\title{
A PRÁTICA DO NUTRICIONISTA EM ESCOLAS MUNICIPAIS DO RIO DE JANEIRO: UM ESPAÇO-TEMPO EDUCATIVO*
}

\author{
The nutricionists practices at elementary schools \\ from Rio de Janeiro: an educative timeless-space
}

\author{
Emília Santos Caniné ${ }^{1}$ \\ Victoria Maria Brant Ribeiro ${ }^{2}$
}

Resumo: Pesquisa qualitativa que analisou práticas e concepções educativas de nutricionistas da equipe de Supervisão Técnica do Instituto de Nutrição Annes Dias - órgão responsável pelo Programa de Alimentação Escolar (PAE), da Prefeitura do município do Rio de Janeiro - e a compreensão que esses profissionais têm do papel que desempenham no Programa. Enfatiza-se o PAE por sua correspondência com a Declaração dos Direitos Humanos, em especial o direito humano à alimentação, e a política de Segurança Alimentar e Nutricional (SAN). Competência e promoção da saúde referenciam a análise das falas - dados da pesquisa de campo - ampliada pelos núcleos de sentido identificados na recorrência de temas: comunicação/informação, trabalho em equipe multidisciplinar, incluindo o controle social, e segurança alimentar e nutricional. Apresentam-se, ainda, as concepções pedagógicas identificadas nas práticas das nutricionistas.

Palavras-chave: Educação em nutrição. Segurança alimentar. Promoção da saúde

\begin{abstract}
This qualitative research has the aim of identifying educational practices and conceptions of nutritionists from the Technical Supervision Team of Instituto de Nutrição Annes Dias, an institution subordinated to the municipality of Rio de Janeiro, responsible for the technical Development of the School Nutritional Program, and the comprehension of these professionals concerning their role in the Program. This Program is identified with the Human Rights Declaration, more specifically with the Human Right to Food and also with the Food and Nutritional Security policies. Competence and health promotion were used as categories previously defined for speech analysis - field research data - enlarged by the following themes: communication/information, multidisciplinary team-work, social control and food and nutritional security and identified in the nutritionists' practices.
\end{abstract}

Key words: Nutritional education. Food security. Health promotion.

\footnotetext{
${ }^{1}$ Elaborado a partir de Caniné, 2005.

${ }^{2}$ Graduada em Nutrição; Instituto de Nutrição Annes Dias (INAD). Rio de Janeiro, RJ. <escanine@ig.com.br>

${ }_{3}^{3}$ Doutora em Educação; docente, pesquisadora, coordenadora, Laboratório de Currículo e Ensino, Núcleo de Tecnologia Educacional para a Saúde, Universidade Federal do Rio de Janeiro (UFRJ). Rio de Janeiro, RJ.

<victorianutes@gmail.com>

${ }^{1}$ Rua Grajau, 91, ap. 101

Rio de Janeiro, RJ

20.561-140 


\section{Introdução}

O estudo parte do pressuposto de que, para além dos conhecimentos técnicos específicos, há no campo da nutrição algo mais simbólico ou subjetivo e voltado para questões sociais. Pela abrangência do campo e pela característica da autoria, aqui se apresenta o recorte da alimentação escolar como espaço educativo.

Quando falamos em espaço, não estamos nos referindo apenas a ambientes físicos, arquitetonicamente definidos, lugares onde podemos estar, mas aqueles que, como refere Mark Wigley (1996), estão vinculados a espaços teóricos, nos quais existem encontros entre pessoas - os chamados espaços sociais como, por exemplo, a família. Em sua origem latina, o termo espaço designava uma extensão do tempo e, portanto, constituía uma noção dinâmica. Com o avanço das tecnologias e dos meios de comunicação, hoje o conceito de espaço geográfico assume essa concepção, na medida em que seu encurtamento, pela velocidade da produção de imagens in time e on line, faz com que se entrelace com o tempo. Com essa concepção de espaço, tentamos compreender o que é possível considerar o espaço-tempo da prática educativa do nutricionista em escolas do Ensino Fundamental.

Considera-se ideal que o nutricionista tenha uma sólida formação pedagógica e a consciência de seu papel de profissional da saúde para, dessa forma, usar o espaço-tempo de sua atividade na escola integrando as duas dimensões - da educação e nutrição -, ampliadas para: educação para a saúde, educação e alimentação saudável, papel da alimentação saudável no Sistema Único de Saúde e outras tantas, desde que não dissolvam este binômio. Basta, para tanto, considerar todo e qualquer espaço-tempo (aqui, especificamente, tratando-se do espaço escolar) como forma de se abrir à exposição, troca de experiências, crítica e ao ensinamento, à maior proximidade com merendeiros, professores, diretores, estudantes e suas famílias, fortalecendo a socialização dos saberes específicos, construindo novos em interação com estes atores e, dessa forma, vivendo a estratégia de educação permanente.

$\mathrm{Na}$ medida em que um espaço é um lugar, mesmo no campo metafórico, é preciso considerar, também, o processo de sua "ocupação". Nesse sentido, o cenário deste estudo é a rotina de trabalho no espaço educativo de escolas do Ensino Fundamental ocupado pelo Programa de Alimentação Escolar (PAE) do município do Rio de Janeiro, no qual adotam-se diferentes concepções pedagógicas e sociais. Compreender e explicar o significado e a abrangência das ações educativas realizadas neste espaço, como estratégias de educação permanente em saúde, foram as motivações iniciais deste estudo.

No caso específico do nutricionista que atua no PAE do Rio de Janeiro, acreditamos que estes espaços devem ser buscados na dinâmica das relações entre as condições materiais de vida e os contextos sócio-culturais de todos os atores nele envolvidos, razão pela qual estas relações estão para além do campo educacional, alcançando o campo político e, como conseqüência, orientadas para a melhoria das condições de saúde da população.

Considerando a especificidade desse estudo, e com base na concepção ampliada de saúde proposta na VIII Conferência Nacional de Saúde (BRASIL, 1987), pretendeu-se: a) explicitar as ações educativas direcionadas a merendeiros, encarregados de merenda e gestores de escolas, realizadas pelas nutricionistas investigadas; b) identificar as concepções pedagógicas que influenciam essas ações; e c) evidenciar, por meio das falas, a compreensão que as nutricionistas (usado aqui no feminino por se tratar de uma equipe composta exclusivamente 
A prática do nutricionista em escolas...

por mulheres) têm do papel que desempenham no PAE, considerando que o programa se insere na política pública descentralizada de saúde, no contexto da Segurança Alimentar e Nutricional (SAN).

$\mathrm{Na}$ verdade, queremos ressaltar a necessidade de tomar como pontos importantes de reflexão diferentes interpretações sobre o que ocorre nesse encontro entre pessoas, fala e escuta que permeiam suas relações, entendendo que escutar implica perceber o outro como indivíduo, compreender e valorizar suas experiências de vida, interpretar seu pensar e agir e, desta forma, proporcionar autêntica troca de saberes (LEITÃO, 1995) e construção conjunta de conhecimentos. Nessa perspectiva, a escuta que valoriza e motiva a fala é uma habilidade/ competência a ser desenvolvida pelos profissionais de saúde (FILGUEIRAS e DESLANDES, 1999), razão pela qual este trabalho deu voz às nutricionistas e suas falas foram transformadas em material da pesquisa.

A abordagem metodológica de natureza qualitativa foi a opção para o estudo, uma vez que o objeto insere-se em um contexto social que, se analisado somente do ponto de vista quantitativo, corre o risco de perder a riqueza do universo de significados, motivos, crenças e valores nele contidos (GURVITCH apud MINAYO, 2000).

No trabalho de campo foi utilizada a técnica de grupos focais - dois com sete e um com cinco participantes - envolvendo dezenove nutricionistas (100\% da equipe em atividade) que atuam no PAE, trabalham no Instituto de Nutrição Annes Dias (INAD) e realizam atividades de supervisão técnica nas unidades escolares da rede municipal de ensino, mais especificamente em visitas às Unidades de Alimentação e Nutrição (UAN), com as seguintes finalidades: controlar a qualidade dos gêneros alimentícios utilizados; avaliar o cumprimento dos cardápios prescritos pelo INAD; avaliar as condições higiênico-sanitárias das instalações, equipamentos e utensílios da UAN; proceder à análise sensorial das refeições preparadas; avaliar a aceitação dos cardápios planejados; e acompanhar o desempenho profissional dos merendeiros. Nessa visita ocorre, ainda, o encontro entre nutricionista, encarregado de merenda e diretor da unidade escolar, momento no qual são indicadas orientações sobre a execução do PAE e discutidos os problemas detectados (INAD, 2002). Realizam-se, também, reuniões periódicas (consultorias) com os responsáveis pela execução do PAE no âmbito escolar e na instância regional (Coordenadorias Regionais de Educação - CRE) para reforçar orientações, discutir problemas e buscar encaminhamentos e possíveis soluções para as dificuldades encontradas.

Como parte do investimento realizado para criar um ambiente saudável na escola, algumas nutricionistas dessa equipe constituem um grupo de trabalho que elabora e revisa normas e especificações de equipamentos e utensílios de uso dos profissionais que manipulam e preparam os alimentos e são parceiras da Secretaria Municipal de Educação (SME) e da RIOURBE (responsável pelas obras nas escolas municipais) no planejamento de plantas físicas das UAN. No que é compreendido como atividade educativa, a equipe promove e participa de cursos, seminários, oficinas, reuniões, encontros informais e palestras para professores, alunos, comunidade, merendeiros e diretores.

Esse elenco de responsabilidades técnicas sobre a segurança alimentar e nutricional e sobre o PAE encobre, muitas vezes, a dimensão educativa que deve constituir uma das principais funções do nutricionista, especialmente no Ensino Fundamental, que representa uma fase mais permeável a ações que se pretendem transformadoras de identidades sociais.

A técnica do grupo focal foi escolhida em razão de sua "inegável importância para se 
tratar questões da saúde sob o ângulo do social" (MINAYO, 2000, p. 129) e enfatizar a importância do entrevistado, que pode se manifestar livremente, em um clima informal de discussão não diretiva, dinâmica e participativa (SUANNO, 2002), garantido o sigilo de sua identidade (neste estudo, as entrevistadas estão identificadas por numeração). Usou-se o recurso da gravação em áudio, com autorização prévia dos participantes, para não se perderem detalhes das falas - dados brutos da pesquisa -, cuja organização e análise foram feitas pelos pesquisadores. Além de ter baixo custo, a técnica permite coleta de dados rápida e eficiente para obter informações qualitativas, quando se conquista a confiança dos participantes para expressar suas opiniões, e é especialmente indicada para diagnosticar problemas potenciais e avaliar processos ou programas em curso (COLARES, 2005; GOMES e BARBOSA, 1999).

As fitas gravadas foram transcritas e analisadas com base nas categorias teóricas prédefinidas - competência e promoção da saúde. Competência porque corresponde aos processos de formação e de atuação profissional. Promoção da saúde por ser finalidade essencial do trabalho no PAE. Conjugadas, as duas categorias permitem analisar a concepção e o desempenho profissional dos participantes e sua relação com o trabalho.

À medida que o material empírico foi se acumulando, outras categorias emergiram das falas, possibilitando, ao final, classificá-las em núcleos de sentido que, de acordo com Minayo (2000, p. 209), “(...) compõem uma comunicação cuja presença ou freqüência significam alguma coisa para o objetivo analítico visado", diferentemente da tradicional análise temática, orientada exclusivamente pela freqüência das unidades de significação.

$\mathrm{Na}$ análise e interpretação das falas, a recorrência de alguns temas destacou os núcleos de sentido: comunicação/informação, trabalho em equipe multidisciplinar - incluindo o controle social - e segurança alimentar e nutricional, todos tendo como pano de fundo o PAE e a competência da equipe que o compõe, no contexto da promoção da saúde.

Dessa forma, o presente estudo justifica-se pelo objetivo de dar visibilidade ao potencial das ações educativas dos nutricionistas, tenham elas caráter normativo ou interativo. Constituem este potencial a competência para a promoção da saúde, o que pode ser matéria de discussão, reflexão e empoderamento dos grupos que atuam no PAE, com possibilidade de reflexos nos demais profissionais do campo da nutrição.

\section{Uma primeira aproximação conceitual}

Se antes afirmamos que o potencial dos nutricionistas inclui competência para promover saúde, cabe uma re-visita a esses conceitos, considerando sua polissemia.

O desenvolvimento de competência no mundo do trabalho está ligado tanto à valorização de maior grau de escolaridade e de se conceber a educação como um processo permanente quanto à inteligência prática dos trabalhadores. $\mathrm{O}$ modelo de competência surgiu na Europa, nos anos 1980, em meio à crise estrutural do capitalismo, com objetivo de reorganizar o processo produtivo e contribuir para recuperar a hegemonia do capital, na produção e na sociedade. Naquele momento viviam-se as conseqüências da revolução tecnológica, que exigia dos trabalhadores requalificação permanente, de modo que mobilizassem seus atributos e capacidades para novas tarefas, em diferentes contextos (DELUIZ, 2001; RAMOS, 2001).

Inicialmente, o conceito esteve ligado a abordagens tecnicistas e mecanicistas, que 
A prática do nutricionista em escolas...

privilegiavam a lista de habilidades de um indivíduo para executar determinada tarefa. Posteriormente, evoluiu para abordagens que articulavam a capacidade intelectual dos trabalhadores a sua valorização como ser humano e o papel das relações interpessoais no resultado final das tarefas. A competência, desse ponto de vista, seria um agir no trabalho valorizando o processo e as relações advindas do encontro de outras competências (outras formas de agir no trabalho), reconhecidas todas (e por todos) como necessárias à realização da atividade ou tarefa.

Várias correntes de pensamento tratam competência de formas diferentes, dando ênfase a aspectos distintos, de acordo com sua linha filosófica. Para Brant (2004) é a concepção de competência que aproxima, estrategicamente, os campos da educação e do trabalho.

Zarafian (1999) considera competência a inteligência (conceitual e prática, indistintamente) individual e coletiva que os trabalhadores demonstram em situações trazidas pelos eventos com toda sua complexidade: eles antecipam a complexidade e dela extraem benefícios para outras situações que possam ocorrer. Sem dúvida, esta concepção corresponde, de modo mais próximo, à que orientou este estudo.

No Brasil, nos anos 1990, começa a ser implementada uma reforma educacional na lógica de reforma das políticas sociais, dentro do contexto neoliberal, subordinando a produção educacional às necessidades de mercado (DELUIZ, 2001). Os programas e currículos escolares são, então, organizados com base na pedagogia da competência, que se identifica com as pedagogias de viés psicológico, como o construtivismo. Mas sobressai o fato de que a "apropriação socioeconômica de uma noção originária da psicologia cognitiva conferiria à educação o papel de adequar psicologicamente os trabalhadores às relações sociais de produção contemporânea" (RAMOS, 2001, p. 27), concepção que se opõe à aqui utilizada que, por estar diretamente relacionada ao contexto e às relações de uma atividade profissional, deve permitir a crítica aos processos de trabalho e às relações deles advindas (RAMOS, 2001). É essa, também, a concepção de competência adotada pelas Diretrizes Curriculares Nacionais (DCN), homologadas em 2001, após amplas discussões e debates com diferentes segmentos das categorias interessadas.

Em breve retrospectiva histórica, desde a Reforma Sanitária, em 1990 (Lei no 8080/ 90), diversos grupos vêm se mobilizando para alterar conteúdos e métodos dos cursos da área da saúde, em virtude de sua obsolescência e da inadequada abordagem que, historicamente, esses cursos vêm adotando. O predomínio da ênfase nos níveis de atenção secundária e terciária, o modelo centrado no hospital, a célebre separação entre ciclos básico e clínico, entre outras, são, sem dúvida, uma espécie de contramão na estrada das necessidades da maior parte da população brasileira, no que diz respeito ao atendimento à saúde.

Paralelamente, o acelerado desenvolvimento científico-tecnológico vem sinalizando a defasagem do modelo escolar centrado na transmissão de um conhecimento cada vez mais renovável, especializado, crescente, e apontando a urgência de inovações, o que levou, em 1996, à promulgação da nova Lei de Diretrizes e Bases (LDB) da Educação Nacional (Lei no 9394/96) que, por sua vez, desencadeou o movimento das DCN.

Esse é o cenário no qual concebe-se este trabalho: de um lado, nova orientação do sistema educacional como um todo; de outro, nova orientação para formar profissionais da saúde, decorrente do vácuo entre necessidades do sistema de saúde e o modelo quase centenário de conformação dos currículos na área da saúde, como concebido a partir do Relatório Flexner, em 1910 (WHO, 2002). 
A implantação das DCN (BRASIL, 2001), implica inovações de práticas pedagógicas mais sintonizadas com ações interativas das unidades formadoras e necessidades e desejos de saúde das populações que, por guardarem viés mais crítico, ainda encontram resistências. Nos cursos de graduação em nutrição, as DCN definem competências e habilidades gerais e específicas do formando egresso/profissional. Entre elas, pela proximidade com o objeto de investigação foram eleitas para este estudo: comunicação, liderança no trabalho em equipe multiprofissional e educação permanente.

A leitura que se faz das DCN deixa nítida a intenção de que as IES formem os profissionais com um perfil generalista, humanista, capaz de dialogar com a sociedade e compreender seu papel social que, do nosso ponto de vista, inclui a dimensão educativa. Nesse sentido, as ações por eles desenvolvidas devem se dirigir à proteção e promoção da saúde, conceitos que ampliam a visão técnica, especializada e curativa da saúde, tradicionalmente incorporada ao perfil dos profissionais desse campo.

Nos últimos vinte anos, o conceito de promoção da saúde ganhou força em países caracterizados por regimes políticos capitalistas neoliberais. Derivou, principalmente, da constatação de que o aumento de gastos na assistência médica não possuía relação direta com a melhoria da saúde da população. Aos poucos, tornou-se evidente a necessidade de implementar políticas governamentais que tratassem de problemas de saúde pública, especialmente aqueles relacionados às doenças crônicas (CZERESNIA, 2003). É claro que os avanços tecnológicos e científicos aumentaram a expectativa de vida dos indivíduos (LEFEVRE e LEFEVRE, 2004). Porém, a questão que se apresenta é se essa "longevidade" vem acompanhada de uma qualidade de vida desejável e satisfatória, dois conceitos com alto grau de subjetividade.

Com a pós-modernidade, as políticas públicas de saúde, principalmente aquelas voltadas para a promoção, sofreram o impacto do processo de globalização que gerou, em países como o Brasil, a convivência com doenças antes consideradas típicas de países desenvolvidos - como obesidade e doenças cardiovasculares - e outras, como desnutrição e anemia, típicas de países subdesenvolvidos (LEFEVRE e LEFEVRE, 2004).

A necessidade de aprofundar e aproximar o conceito de promoção da saúde das práticas vigentes impulsionou a ocorrência de vários eventos internacionais, dos quais destacamos a Conferência Internacional sobre Atenção Primária de Saúde (em 1978), da qual se originou a Declaração de Alma Ata, e a I Conferência Internacional sobre Promoção da Saúde (em 1986), que deu origem à Carta de Ottawa, referência para o conceito de promoção da saúde. No Brasil, a VIII Conferência Nacional de Saúde (1986) transformou-se em marco histórico ao incorporar o conceito ampliado de saúde em seu relatório final, considerando o conjunto de fatores determinantes e condicionantes do meio físico, os fatores biológicos e a oportunidade de acesso aos serviços que visem à promoção, proteção e recuperação da saúde (BRASIL, 1990).

É nesse contexto que a promoção da saúde se apresenta, avançando na forma de compreender a relação saúde/doença, trazendo para discussão a complexidade do problema e envolvendo outros setores capazes de promover ações que levem a condições adequadas de habitação, renda, alimentação, paz, ecossistema sustentável, recursos sustentáveis, justiça social e eqüidade (WHO, 1986).

Com essa perspectiva, a promoção da saúde consiste em proporcionar à população as condições necessárias para que possa alcançar um estado de bem-estar físico, mental e social, 
A prática do nutricionista em escolas...

além de possibilitar o desenvolvimento da capacidade de o indivíduo - ou grupo - exercer mais controle sobre sua saúde (CAMPOS, 2003). O conceito é complexo porque envolve decisões que não podem ser tomadas isoladamente. $\mathrm{E}$, nesse sentido, aquele para o qual se dirigem as ações precisa ser ouvido. Entendemos, ainda, que, se o Estado deixa de assumir seu papel na complexidade de promover a saúde e coloca essa responsabilidade exclusivamente nas mãos da sociedade, se algo acontecer a culpa é do povo. Nada melhor para destruir qualquer idéia de autonomia e de empoderamento.

Acreditamos na importância de políticas públicas intersetoriais que ultrapassam o campo específico da saúde. O diálogo intersetorial é complexo e possível apenas quando existem respeito e valorização mútuos. Apesar das dificuldades, justifica-se o investimento em ações intersetoriais pois, quando implementadas, permitem a identificação de problemas coletivos e facilitam a busca de soluções integradas para problemas de saúde (AERTS et al., 2004).

De acordo com Campos (2003), essas ações fazem emergir problemas da comunidade, os quais podem transformar-se em pautas positivas para promoção de saúde. Nesse caso, a educação e a informação para a saúde passam a ser fundamentais, à medida que aumentam a consciência sanitária dos cidadãos e intensificam sua participação na definição de prioridades. Nessa mesma direção encontra-se a concepção de controle social aqui adotada.

O duplo sentido da expressão vem sendo fortemente discutido em paralelo à consolidação da democracia no país. Utilizado por alguns autores como o controle do Estado sobre a sociedade, com objetivo de amenizar ou evitar conflitos (CORREIA, 2000), deixa clara a interferência governamental e dos meios de comunicação nas ações sociais (VALLA, 2002). O sentido usado neste estudo é aquele defendido por Valla (2002) e Correia (2000) como o controle público exercido pela sociedade civil organizada e de caráter popular: uma tarefa árdua de construir um processo que inclua as classes populares na participação efetiva das decisões da nação (VALLA, 2002). Embora um dos focos seja o PAE, tomado como política pública e programa de governo, a idéia é que ele seja um instrumento, em menor escala, que possibilite a inserção da comunidade nas decisões sobre alimentação, deixando as escolhas a cargo da população organizada, em maior escala, conforme seus desejos e necessidades.

Desse modo, a comunidade precisa ser ouvida para ser compreendida. O conhecimento de seus direitos e deveres é fundamental para exercitar sua autonomia no momento de realizar escolhas que remetam a melhores condições de saúde. É necessário, entretanto, que o poder público garanta espaços onde sejam possíveis a mobilização e o exercício do controle social, mediante o acesso à informação.

Nesse aspecto, o conceito de empoderamento ganha força, quase como causa e conseqüência do controle público, na medida em que se refere à capacitação da sociedade civil organizada e de caráter popular em conhecimentos que, em geral, são de domínio exclusivo dos profissionais. Empoderar, portanto, os grupos que atuam no PAE significa tornar competentes tanto as nutricionistas, nos conhecimentos da experiência da população, quanto a população beneficiada pelo programa nos conhecimentos específicos da nutrição. Para tanto, a Organização Pan-Americana sugere que estratégias de "empoderamento" da comunidade supõem, entre outras iniciativas, educação para a cidadania, socialização de informações, envolvimento na tomada de decisões dentro de um processo de diagnóstico, planejamento e execução de projetos e ou iniciativas sociais (OPAS, s/d). 


\section{Ancoragem teórica da prática educativa do nutricionista no PAE}

Considerando que o tema escolhido integra duas práticas sociais com amplo apoio teórico em diferentes campos do saber é chegado o momento de explicitar as concepções eleitas para sustentá-las, de modo a dar sentido e confiabilidade à evidência de que a prática do nutricionista que participa do PAE é eminentemente educativa.

Quanto às concepções educativas dos nutricionistas, pode-se afirmar que são frutos da vivência pessoal e das relações que mantêm com as instituições nas quais trabalham: escolas, INAD, SME, SMS.

Considerando que diferentes abordagens pedagógicas convivem, simultaneamente, nos espaços educativos, optamos por caracterizar as que mais influenciam a prática educacional no campo da saúde, a fim de tornar claras as concepções encontradas na investigação de campo.

Antes, porém, cabe destacar que a classificação adotada para as abordagens segue, relativamente, a taxonomia de Libâneo (1985) em relação às tendências das práticas pedagógicas presentes na educação brasileira - que, como se sabe, guardam certa cronologia. Situam-se no grupo das pedagogias liberais a concepção tradicional e a comportamentalista (não-diretiva), voltadas para a manutenção e reprodução do sistema capitalista. No grupo das pedagogias progressistas encontram-se as concepções contrutivista e político-social que, partindo da análise crítica da realidade, procuram construir com as camadas populares instrumentos intelectuais que lhes sejam úteis na luta pela transformação social. Embora não se possa afirmar a fidelidade absoluta dessas concepções aos períodos históricos brasileiros, é possível delimitálas pelo marco do ano 1980, período de transição democrática, que correspondeu à culminância do movimento de crítica à pedagogia tradicional e a seus correlatos, em especial o humanismo e o tecnicismo.

Entre as concepções que entendem a educação como instrumento capaz de tornar a sociedade mais harmoniosa e homogênea, superando a marginalidade (no sentido de ignorância), encontra-se a tradicional (VALENTE, 1989), que privilegia a transmissão, o armazenamento e a acumulação de informações e defende que o indivíduo só poderá conhecer o real por meio de conhecimentos adquiridos. Aqui não existe comunicação entre os sujeitos e, sim, comunicados feitos pelo educador, considerado aquele que sabe.

$\mathrm{Na}$ verdade, alguns educadores acreditam estar educando quando realizam exposições teóricas, prévia e unilateralmente escolhidas, ignorando que "só existe saber na invenção, na reinvenção, na busca inquieta, impaciente, permanente, que os homens fazem no mundo, com o mundo e com os outros" (FREIRE, 1984, p. 66).

Outra abordagem não crítica de educação é a comportamentalista ou behaviorista, nascida com base nos pressupostos filosóficos positivistas e na psicologia experimental. $\mathrm{O}$ positivismo tende a consolidar a ordem pública por meio do desenvolvimento da resignação, pois, para aceitar os problemas sociais sem contestação, é necessário que se creia na existência de leis inevitáveis, as quais não podem ser desrespeitadas e combatidas (MINAYO, 2000). Seguindo essa tendência, os comportamentalistas acreditam que o conhecimento é resultado direto da experiência que se situa entre estímulos e respostas, produto previsível, observável e passível de descrição, fruto de experiências planejadas fora do sujeito, sem qualquer preocupa- 
A prática do nutricionista em escolas...

ção com sua "consciência" e com seu "espírito" (ABBAGNANO, 2003), razão pela qual consideram que o homem pode ser moldado segundo estímulos do meio ambiente (MIZUKAMI, 1986).

Em oposição às concepções não críticas, a concepção construtivista admite que existe um mundo real, sem desconsiderar que cada indivíduo atribui a ele significados particulares, de acordo com seus processos mentais. Os ambientes construtivistas permitem aos indivíduos interagir com o meio. Somente quando a interação ocorre o conhecimento se efetiva. Este é um modelo flexível, no qual a certeza cede lugar à incerteza e ao possível desequilíbrio, demandando constantes readaptações durante o processo de aprendizagem (STRUCHINER et al., 1998). Dessa forma, o conhecimento é visto como processo ativo e contínuo, que envolve operações, combinações e reorganizações mentais. Os construtivistas valorizam as relações sociais sendo, portanto, necessário desenvolver habilidades que possibilitem a interação com o grupo.

Ainda no extremo que se contrapõe às concepções não críticas, a abordagem políticosocial faz crer que apenas por meio da transformação da realidade se realiza a educação. Nesse sentido, a educação exige conscientização dos atores envolvidos, o que se faz por meio do diálogo democrático, que permite negociar as relações de poder. Isto configura uma relação de ensino e de aprendizagem baseada em processos dialógicos. As relações estão condicionadas a circunstâncias sociais, culturais, econômicas e políticas e, em cada indivíduo, geram concepções distintas, com aproximações e com distanciamentos de sentidos que podem comprometer a "unidade" do trabalho a ser desenvolvido. No Brasil, Paulo Freire foi o pioneiro dessa pedagogia, que tem por objetivo possibilitar a participação das camadas socioeconômicas desfavorecidas da população no processo político-cultural (SCHALL e STRUCHINER, 1995).

Por suas características reflexivas e dialógicas, este tipo de abordagem ganha força na educação de adultos, podendo estar a serviço da prática das nutricionistas em relação aos demais profissionais com os quais atuam nas escolas municipais, espaços em que se desenvolvem ações de Segurança Alimentar e Nutricional (SAN), aqui compreendida como referência para analisar a política de alimentação escolar.

Com um olhar mais atento sobre a alimentação, verificamos que o ato de comer está repleto de significados que transcendem o fato de satisfazer a fome e as necessidades nutricionais. É necessário compreender que as escolhas alimentares estão ligadas a aspectos objetivos - como quantidade de alimentos produzidos, renda, qualidade dos alimentos, entre outros -, mas, também, a aspectos subjetivos - como gosto, prazer, valores, relações sociais, questões relativas à busca, ao consumo e à proibição de certos alimentos -, que necessitam ser explicados em cada contexto, em cada época.

Tendo em vista a magnitude da alimentação humana, entendemos ser necessário o acesso da população a informações sobre princípios de uma alimentação saudável, no sentido de aumentar sua autonomia no momento da escolha dos alimentos que farão parte de seu regime alimentar. Desse modo, o conhecimento sobre práticas alimentares saudáveis pode contribuir para minimizar problemas do nosso dia a dia.

Considerando, entretanto, que as normas dietéticas - "formadas por um conjunto de prescrições apoiadas em conhecimentos científicos nutricionais" - são influenciadas e influenciam as normas sociais - "convenções relativas à composição estrutural das tomadas alimentares e às condições e contextos de seu consumo" (POULAIN, 2004, p. 82) -, torna-se neces- 
sário ter cautela com a supervalorização das prescrições meramente técnicas que podem gerar um abismo entre a teoria e as condições de vida, na medida em que ignoram a função estruturante da alimentação na organização dos grupos sociais (op cit.). As práticas alimentares que respeitam as diferenças culturais e são capazes de se sustentar social, econômica e ambientalmente podem ser consideradas promotoras de saúde, da mesma forma que o acesso regular e adequado a uma alimentação saudável é um direito humano. Esse direito é o princípio fundamental da SAN.

No Brasil, a discussão sobre segurança alimentar teve início, ou pelo menos ganhou visibilidade, em 1985, com foco na agricultura quando, então, esboçou-se uma primeira proposta de Política Nacional. Em 1986, realizou-se a I Conferência Nacional de Alimentação e Nutrição (BRASIL, 2003), na qual ficou estabelecido o conceito de segurança alimentar que integra o abastecimento em quantidade adequada, o acesso universal e os aspectos nutricionais dos alimentos (BRASIL, 1999).

Em 1994 foi realizada a I Conferência Nacional de Segurança Alimentar e, dez anos mais tarde, em 2004, a II Conferência Nacional de Segurança Alimentar e Nutricional (BRASIL, 2004), que ratificou a necessidade de valorizar ações educativas que levassem a práticas de alimentação saudável, como indicado na Política Nacional de Alimentação e Nutrição (PNAN), aprovada em 1999 e ratificada em 2003, sem qualquer alteração: "o desenvolvimento e a capacitação de recursos humanos constituem diretriz que perpassará todas as demais definidas nesta política" (BRASIL, 1999, p. 27).

No âmbito municipal, segundo estudo desenvolvido por Valente (2002), existem cinco diretrizes básicas que devem ser consideradas para que se consiga promover a SAN:

promover a produção e a comercialização de alimentos de forma socialmente eqüitativa; ampliar o acesso à alimentação de qualidade e regular as condições para tornar disponíveis os alimentos à população; promover a educação alimentar e a organização dos consumidores, com vistas a incentivar a defesa de seus direitos; universalizar os programas alimentares suplementares dirigidos a grupos específicos da população; estimular a participação da sociedade civil em todas as fases da política de SAN e apoiar as iniciativas não-governamentais. (p. 134)

Entre as diretrizes, destacamos aquela que trata dos programas alimentares suplementares, pelo fato de nela estar contido o PAE, e tem como objetivos: universalizar e regularizar o oferecimento de refeições; promover hábitos alimentares saudáveis e diversificados e introduzir componentes de segurança alimentar; fortalecer a representatividade e a participação dos Conselhos de Alimentação Escolar (CAE).

\section{Programa de Alimentação Escolar no município do Rio de Janeiro: o espaço-tempo da prática educativa}

Criado em 13/10/1956, com o nome de Instituto Municipal de Nutrição, subordinado à Secretaria Geral de Educação e Cultura, o INAD foi fruto do reconhecimento das grandes dimensões do programa no município do Rio de Janeiro e da vocação para as atividades 
A prática do nutricionista em escolas...

educativas, o que pode ser evidenciado na divulgação de informações relativas a alimentação e higiene alimentar em boletins informativos distribuídos às escolas.

Em 1995, ao passar a integrar a estrutura organizacional da Secretaria Municipal de Saúde (SMS-RJ, 1995), o INAD incorporou a suas funções originais, exclusivamente ligadas à alimentação escolar, outras relativas aos programas de nutrição de diversas secretarias. Seu leque de atribuições foi, então, ampliado consideravelmente, na medida em que passou a ter, sob sua responsabilidade, a missão de integrar as ações de nutrição no município do Rio de Janeiro.

Ao longo dos anos, o instituto demonstrou seu pioneirismo como órgão técnico em nutrição, especialmente ao perceber no PAE seu potencial para ações promotoras de saúde, considerando-se o sentido ampliado desse conceito. Foi nesse contexto que o INAD obteve reconhecimento nacional e internacional.

Atualmente, no que se refere ao PAE, o INAD propõe e promove estratégias que visam sensibilizar os diferentes segmentos da comunidade escolar para que desenvolvam e se integrem às ações que valorizem e promovam a saúde do merendeiro, comprometam gestores (especialmente diretores) e representantes locais, discutindo conceitos de alimentação saudável e refletindo sobre comportamento alimentar, inovações importantes em tempos de globalização, que descaracteriza a cultura alimentar de cada grupo social. Quanto aos objetivos, o PAE do município do Rio de Janeiro, pretende: “(...) garantir o acesso dos alunos do Ensino Fundamental da rede pública de ensino a uma alimentação saudável, visando a promoção da saúde e o pleno desenvolvimento deste segmento da população, assumindo, como premissa, que a alimentação é um direito humano" (INAD, 2005, p. 4).

Por ser política pública, o programa espera contar com efetiva participação da comunidade em todas as fases de seu desenvolvimento - do planejamento à execução. Isso implica envolvimento de todos os atores, esclarecidos sobre seus objetivos e suas ações, para o que tornam-se fundamentais a informação e a comunicação. E informação compreendida como um dos componentes da promoção da saúde que permite capacitar a sociedade para tomar decisões autônomas visando à melhoria da qualidade de vida. Deste ponto de vista, informar não pode ser confundido com conduzir, na medida em que a informação está baseada no diálogo e, a condução, na persuasão (LEFEVRE e LEFEVRE, 2004).

$\mathrm{Na}$ prática profissional das nutricionistas que atuam nas escolas, sujeitos deste estudo, algumas vezes encontra-se uma postura autoritária e verticalizada, nem sempre intencional, que coloca o raciocínio científico acima dos saberes populares dos grupos com os quais se envolvem, contrária aos princípios do diálogo.

Especulamos se este modo de atuar está baseado na concepção tradicional de educação e na idéia de que o saber popular é uma forma falsa de conhecimento e, desse modo, deve ser ignorado. Nossa suposição surge tendo em vista que algumas profissionais pesquisadas consideram o saber científico relativo à nutrição propriedade do nutricionista, conforme declaração de uma delas.

"Se você pegar uma nutricionista para falar sobre alimentação saudável e até mesmo sobre alimentação escolar, a informação vai ser encarada de maneira diferente, pois todos sabem que o nutricionista é o titular daquela especialidade de saber. Então, existe diferença quando um professor fala e quando um nutricionista fala". (N.5) 
"(...) nós trabalhamos com material informativo para os professores, para que eles repassem para os alunos. Só que existe algo além disso. Eu acho que o ideal seria o nutricionista passar a informação diretamente. Ele passaria melhor do que um profissional que não é o "detentor do saber" dessa área. Acho que o ideal seria esse, o nutricionista, assumir o papel de educador, atuando com o seu cliente direto e não repassando informações". (N.5)

Os depoimentos revelam a concepção clássica (ou tradicional) de educação, manifesta quando se considera que existem locais específicos para a relação educar/aprender, relação baseada na transmissão de conhecimentos.

“(...) educação tem a ver com transmissão de conhecimento (...). Então, é diferente quando você está na visita técnica transmitindo conbecimento para a diretora, para encarregado de merenda e para a merendeira, do que quando você tem uma ação educativa e pedagógica com espaço, com tempo, com atividades planejadas que visam atingir um objetivo final”. (N.2)

Na maioria das vezes, o senso comum tem sua importância desprezada para grupos em estado de subordinação, que fazem dele uma forma de resistência (SANTOS, 1989), uma vez que as "prescrições" são consideradas, por esses grupos, intromissões de natureza técnica, objetiva e impessoal em fatores afetivos, subjetivos e pessoais (LEFEVRE e LEFEVRE, 2004). Daí a complicada relação conhecimento comum/conhecimento científico, especialmente em processos nos quais é necessária uma relação cooperativa entre cumprimento de normas técnicas e respeito ao conhecimento pré-existente do grupo ao qual elas se destinam.

"Eu acho que no momento em que você fala com o merendeiro e ele diz que não sabe nada sobre aquele assunto, devemos questionar: 'há quanto tempo você está trabalhando? Quantas vezes você participou de um curso? Vocêparticipou desse último curso?' Eu nunca chego e digo que ele está errado. Eu pergunto sobre o que ele sabe, sobre a sua prática. Ai eu estou relembrando o conhecimento dele". (N.1)

Lefevre e Lefevre (2004) alertam, ainda, que mesmo a divulgação dialogada de informações pode ser limitada pela baixa escolaridade do grupo ao qual se dirige, visto que existe um abismo entre os informadores e informados. No estudo, pudemos verificar que as nutricionistas entrevistadas defendem o direito à informação, pois “(...) sem informação a pessoa não tem como utilizar bem os recursos de que dispõe, não sabe como reivindicar seus direitos de cidadão, os direitos à saúde também" (N.4). "Informação é tudo mesmo". (N.14)

Inicialmente, a adequação da linguagem ao contexto cultural do interlocutor é um exercício que merece empenho por parte dos profissionais, mas é deles a tarefa primordial de torná-la o mais próxima possível da linguagem "culta", aqui entendida como a daqueles que usam o poder para submeter as camadas populares a seu domínio. As entrevistadas mostraram-se dispostas a romper esse abismo, como se pode verificar nas falas de algumas.

"A forma que a gente vai trabalhar, a linguagem que a gente vai usar, a abordagem pedagógica que a gente vai ter com a criança é totalmente diferente daquela que a gente vai ter com o professor, por exemplo". (N.2) 
A prática do nutricionista em escolas...

"(...) depende do jeito como você divulga a informação e como você a utiliza. O importante é

discutir”. (N.14)

Habermas (1990, p. 72) afirma que a linguagem dirigida ao entendimento, usada como fonte de informações e também como meio de integração social, é um agir comunicativo. $O$ acordo obtido consensualmente está apoiado na "força racionalmente motivadora de atos de entendimento".

Ao nos referirmos à ação comunicativa, reportamo-nos às DCN do curso de graduação em nutrição, nas quais encontramos a comunicação como uma das competências gerais do formando egresso/profissional, como já descrito. Segundo Brant (2002, p. 9), “(...) competência comunicativa diz respeito à capacidade dos falantes, em uma comunicação, de utilizarem argumentos válidos, corretos e sinceros visando um acordo consensual, negociado, livre de coação, ou seja, com poder de convencimento, exclusivamente pela força dos argumentos, sem qualquer tipo de dominação".

A importância do convencimento foi demonstrada na fala a seguir. Porém, não foi possível avaliar se o convencimento está apoiado em uma argumentação que considera os dissensos constatados e se os planos de ação são definidos cooperativamente entre ouvintes e falantes. Caso essas condições de fala estejam presentes na rotina da nutricionista teremos um avanço em direção à ação comunicativa.

"Você tem que convencer a pessoa sobre a importância daquele procedimento. É um processo de convencimento, é explicar realmente por que aquele procedimento deve ser feito. A pessoa precisa entender por quê e como deve ser feito". (N.4)

Outra questão identificada no estudo foi a divulgação da informação como forma de possibilitar o aumento da autonomia dos indivíduos - no caso do PAE, os alunos - na escolha de alimentos e de preparações saudáveis.

"Para o aluno fazerer escolhas saudáveis, em termos de alimentação, precisa ter informação. Seria basicamente isso, informarpara que as pessoas possam modificar hábitos e torná-los mais saudáveis". (N. 10)

Cabe, aqui, lembrar Czeresnia (2003), que alerta para o fato de que nem sempre é possível alterar hábitos somente por meio da informação, pois, como já vimos, existem diversos determinantes envolvidos no comportamento alimentar dos indivíduos.

Com base no pressuposto da necessidade de tornar disponíveis as informações para que a comunidade possa exercer seu direito de participação, outra questão que investigamos foi quanto as nutricionistas que atuam na supervisão técnica estão conscientes de seu papel no PAE e da dimensão política e social do programa.

"Eu entendo o programa. Eu o entendo como política pública. Eu defendo o público, não só da educação, mas também o público da saúde (...). Então, eu acho que aqui todas temos a consciência da importância do programa como politica pública de nutrição”. (N.6) 
Mas também encontramos relatos nos quais o PAE é descrito, apenas, como meio de amenizar o baixo poder aquisitivo de parte da população, na medida em que diminui os gastos familiares com a alimentação dos filhos em idade escolar. Na íntegra, a fala de uma nutricionista sintetiza este pensamento.

"Se o pai hoje tivesse um salário digno, estaria tudo bem. Acho que é como se estivesse tampando o sol com a peneira para mostrar para o pai: 'estou dando merenda, não precisa reclamar'. Antigamente, a merenda era mingau e os pais recebiam salário digno e mantinham a alimentação da criança dentro do padrão”. (N.1)

Nesta fala, além do aparente desconhecimento do princípio da universalidade do PAE, encontramos a afirmativa incorreta de que, inicialmente, o programa oferecia preparações simples devido ao salário "digno" dos pais. Ao contrário do exposto nesta fala, o PAE nasceu com caráter assistencialista, em um contexto no qual a escola pública não era para todos, tendo sido implementado timidamente com os recursos das caixas escolares e, posteriormente, com a ajuda de organismos internacionais. Atualmente, possui destinação orçamentária prevista para atendê-lo e ganhou importância no contexto amplo da SAN. É verdade que a oferta de refeições possui destaque nas atividades do PAE e é inspirada no direito humano à alimentação, no sentido de garantir, ao aluno, pelo menos no período em que permanece na escola, acesso a uma alimentação segura e equilibrada, em quantidade e qualidade adequadas, direito reconhecido por uma das entrevistadas.

"De uns tempos para cá está se tentando mudar o conceito e o caráter de assistencialismo e de paternalismo do PAE para a questão do direito humano à alimentação. O programa não deve ser entendido como ajuda do governo para os pobres: 'coitadinho, vou dar comidinha para ele'. O programa é um direito do aluno, assim como é um direito nosso trabalhar oito horas por dia e parar para almocar". (N.15)

Ainda que a garantia de acesso ao alimento seguro seja parte do programa, cresce cada vez mais a importância destinada à função educativa do PAE, a escola considerada espaço propício à formação e divulgação de hábitos alimentares saudáveis. Apesar de considerarem a importância da educação, algumas nutricionistas ponderam que, diante dos problemas socioeconômicos da população, é muito difícil priorizar aspectos educativos nas visitas técnicas.

"Eu acho que o lado social acaba superando o lado educacional. (...) Lógico que o educacional vai favorecer o social, mas no contexto atual você acaba ficando sufocada, entendeu? Você tem que atender a tantos problemas que o papel educacional, que seria o mais importante, acaba ficando em segundo plano". (N.17)

A falta de consenso sobre o que deve e pode ser feito aumenta à medida que, ao ampliar seu campo de ação, o nutricionista é tensionado a desenvolver atividades de caráter exclusivamente técnico, que não devem ser consideradas secundárias, e outras, voltadas para a educação alimentar e nutricional. Embora considerando que não pode abrir mão de zelar pelas qualidades nutricional e higiênico-sanitárias dos alimentos e das refeições servidas, pois é o 
A prática do nutricionista em escolas...

responsável técnico pelo programa, entendemos que esteja em jogo a forma de conciliar novas e velhas atribuições em um contexto, muitas vezes, desfavorável, em função das dificuldades existentes quanto ao número reduzido do quadro de pessoal, às instalações das UAN nas escolas, entre outras. Perante as diversas atribuições inerentes ao funcionamento do PAE, torna-se difícil visualizar a relevância de aspectos que dizem respeito à divulgação de informações sobre promoção da alimentação saudável e, conseqüentemente, da saúde. Entretanto, mesmo pressionadas pela rotina do dia a dia, as nutricionistas percebem o quanto o programa pode contribuir para a criação de novos hábitos alimentares que levem à melhoria da qualidade de vida.

"Nas creches, as diretoras relatam como as crianças melhoram, como as crianças levam para casa a questão dos horários das refeições e dos gêneros usados no almoço (...)”. (N.16)

Ao mesmo tempo, mostram a importância de comprometer os gestores da escola - a quem cabe definir prioridades sem descuidar das outras questões que permeiam o espaço escolar - com o programa, mesmo encontrando algumas dificuldades.

"O fundamental mesmo é ter a direção como aliada. No momento em que a direção aceitar o programa, ela vai fazer tudo isso que a gente acha importante". (N.7)

"Na última visita que en fir. o diretor passou um descrédito tão grande quanto ao programa que me deixou desanimada. Ele achou que havia coisas mais importantes, ele tinha muitos problemas com a comunidade, com segurança, falta de material”. (N.11)

Do nutricionista, espera-se que seja sensível aos problemas reais, enfrentados no dia a dia da escola, e que busque apresentar soluções viáveis para situações que podem ser resolvidas dentro da unidade e parcerias para aquelas que extrapolam as possibilidades de resolutividade interna.

"Precisamos convencer o diretor a tentar resolver as coisas que estão ao alcance dele. Providências simples podem ser tomadas e podem melhorar muito o atendimento aos alunos". (N.10)

"De modo geral, as nutricionistas entendem que a relação com o gestor deve ser de parceria, (...) quebrando o gelo aos poucos, sem impor suas idéias, em geral pré-concebidas. Há de se conquistar a direção”. (N.8)

Neste estudo, parceria deve ser entendida como o oposto à fiscalização. O que percebemos é que, apesar de atuarem no mesmo programa, as nutricionistas não possuem o mesmo entendimento sobre suas atribuições. As divergências de entendimento geram posturas conflitantes, que se manifestam no relacionamento entre nutricionistas e comunidade escolar, como ilustram as falas:

"Nós insistimos que não somos fiscalizadoras". (N.15) 
"Em todas as visitas que en faço, deixo claro que men papel é fiscalizar, sim. Eu quero saber se o que nós planejamos está chegando ao prato da criança”. (N.9)

Percebemos que quando as nutricionistas são vistas como parceiras existem mais possibilidades de compartilhar experiências educativas relacionadas à alimentação.

"Teve uma Feira de Ciências em uma escola e nós fomos convidadas para dar uma palestra. Como a clientela da escola é do Jacaré, as professoras foram até lá, chamaram as mães e fizeram um trabalho junto com a pastoral (...) E ai , no dia da palestra estavam presentes pessoas da pastoral, mães de alunos, enfim, foi um trabalho que envolveu os alunos e a comunidade. As crianças desenvolveram vários trabalhos, até funcionaram como repórteres, filmaram a palestra e nos entrevistaram. Fiz̨eram o TV Saúde e colocaram a nossa cara na televisão. Um professor fez um "rap da alimentação saudável" (...). Eu lembro que eu visitava essa escola antes e muitas crianças levavam lanchinho; após esse trabalho feito junto com as merendeiras, com os pais, com todo mundo, a alimentação dos alunos está melhorando". (N.18)

Uma das principais dificuldades apresentadas pelas nutricionistas para atuar como parceiras da escola e "conquistar" a confiança da direção, sensibilizando-a para a importância do PAE, é o grande intervalo entre as visitas realizadas, fato justificado pelo número insuficiente de profissionais lotados no INAD.

"Nós esbarramos no nosso quantitativo. Enquanto nós tivermos esse quantitativo, nunca vamos poder atuar como desejamos". (N.19)

"Mas o processo educativo não é contínuo? Como ele pode ter continuidade se, depois de uma visita, ela só vai se repetir no próximo ano?’'. (N.11)

Relevante citar a participação da comunidade, como forma de controle social das políticas públicas, principalmente quando existe dificuldade para sensibilizar o gestor quanto à sua responsabilidade no desenvolvimento dos programas de governo. As falas que se seguem sugerem, então, o oposto do que vinha sendo expresso até o momento: ou seja, independente do comprometimento da direção, o papel do nutricionista é esclarecer a comunidade sobre as diretrizes e funcionamento do programa, para que, desta forma, possa vir a assumir uma posição de protagonismo na execução do PAE.

"Às vezes você senta com a direção e ela está olhando para você, mas com a cabeça em outra coisa. No momento da visita é complicado dizer que temos uma atuação no sentido de estar educando, sensibilizando (...) acho que seria muito interessante se tivéssemos nosso foco mais direcionado para a educaşão nutricional planejada para o trabalho com os professores, com os alunos, com a comunidade (...) Assim, estaríamos sensibilizando, não só quem está ligado diretamente à merenda, mas também à própria comunidade. E a própria comunidade exigiria da escola o cumprimento do programa. Acho que deve ser o movimento contrário do que costumamos fazer, principalmente quando não existe comprometimento da direção, a comunidade precisa ser envolvida”. (N.2) 
A prática do nutricionista em escolas...

"Eu acho que é o seguinte: vamos sensibilizar a massa para a massa sensibilizar o gestor da escola. É o movimento contrário". (N.5)

Entendemos, entretanto, que, para a maioria das nutricionistas, é difícil conviver com práticas relativamente novas de participação popular e descentralização de poder. É inevitável perceber que o conceito de empoderamento não é aceito por todos os profissionais, uma vez que a formação na área da saúde, fragmentária e com ênfase na especialização, não favorece o trabalho intersetorial nem multidisciplinar requisitado pela sociedade. À formação fragmentária, acresce-se a dificuldade de lidar com a difusão da informação e a necessidade, algumas vezes excessiva, de marcar seu espaço profissional. Desse modo, o trabalho em equipe multidisciplinar dificilmente será visto como intercessão de práticas.

"Eu não sei se o certo é contar tudo para todo mundo. Abrir o leque, dar as instruções todas para todo mundo. Ou se o certo é ficar cada um no seu canto: "isso não me compete e eu não vou dar palpite, eu não vou dar sugestão nisso'. Eu, sinceramente, não sei em qual dos dois lados agir, porque eu acho que quanto mais gente souber sobre o programa é melhor. Então, eu acho que é um pouco de corporativismo ficar assim: 'não, isso é meu, eu não conto para ninguém, isso é o papel do nutricionista'. Eu não sei o quanto isso é positivo ou negativo, não tenho essa avaliação ainda, mas que o papel de cada um tem que ser esclarecido tem. Porque é incrivel: o programa existe há cinqüenta anos e ninguém sabe o que é de quem ainda (...)". (N.15).

Por valorizarmos o trabalho em equipe e considerarmos o Conselho de Alimentação Escolar um parceiro importante no contexto do PAE, acreditamos que as nutricionistas precisam ter clareza das atribuições desta entidade, assim como ser por ela "legitimadas", para que possam atuar conjuntamente, evitando constrangimentos causados por falta de conhecimento do verdadeiro papel de cada um.

Vale ressaltar que, embora em nível nacional, as funções do CAE estejam bem definidas pelo Fundo Nacional de Desenvolvimento da Educação (FNDE), algumas superpõem-se às funções dos nutricionistas em nível local, fato que contribui para o pouco entendimento dos respectivos papéis, muitas vezes gerando conflitos e insegurança no desenvolvimento de ações que deveriam ser conjuntas e interferindo na rotina da escola, uma vez que podem ocorrer informações e orientações divergentes.

"Tinha que ter maior entrosamento entre nós e o CAE. Às vezes, eles fazem certos tipos de colocações que são contrárias ao nosso trabalbo (...) Eu acho que, em algum momento, nós temos que sentar e conversar. Eu não sei como (...)". (N.19)

Como solução, as nutricionistas propõem buscar mais entrosamento com os conselheiros e entendem que o reconhecimento recíproco do trabalho ocorre, mais facilmente, quando existe aproximação nas atividades cotidianas.

"Eu acho que nós deveriamos abrir mais, chamar as pessoas, conversar, explicar até que ponto nós podemos atuar, até aonde elas podem estar contribuindo conosco, mas sempre respeitando, sabendo que existe uma área técnica que nós somos capazes de resolver algumas coisas e que elas podem entrar como parceiras, mas não interferindo (...)" . (N.16) 
Embora considerando as dificuldades apontadas, próprias de países como o Brasil, nos quais a gestão participativa é uma forma de governo relativamente nova, já encontramos relatos que reconhecem e entendem a responsabilidade que o CAE possui no que diz respeito ao controle social do programa.

"O Conselho de Alimentação Escolar é o controle social do Programa de Alimentação Escolar, assim como temos o Conselho Municipal de Saúde, Distrital de Saúde, enfim (...) é a participação da comunidade e do poder público também (...)". (N.15)

Compreendendo a responsabilidade e o compromisso (ou dever) que o INAD tem de somar esforços, reunindo parceiros para concretizar os objetivos do programa, e considerando que o aluno é sempre o sujeito final que o PAE deseja atingir, entendemos que os meios empregados para alcançá-lo é que variam.

"O aluno é o alvo. Forma-se uma equipe e essa equipe deve estar toda voltada para o trabalho com os alunos". (N.13)

Uma das grandes preocupações das nutricionistas é relativa à oferta de um alimento seguro, fato que justifica a tendência higienista das orientações aos merendeiros.

"Eu acho que a educação nutricional passa muito pela orientação dada à merendeira com relação à higiene: controle da bigiene, higiene pessoal, controle da bigiene do ambiente, higiene dos utensilios, bigiene no preparo". (N.3)

É nesse sentido que cresce a responsabilidade do nutricionista, pois são muitos os "tentáculos" que se abrem em sua atuação. Para ressaltar apenas os principais: ficar atento às condições higiênico-sanitárias do alimento e do ambiente em que é preparado, ao modo como é preparado e distribuído e, ao mesmo tempo, responsabilizar-se pela divulgação de informações sobre alimentação saudável, pela formação de hábitos alimentares saudáveis com vistas à promoção da saúde. Enfim, o nutricionista é chamado - e não pode se omitir - a participar do importante e atual movimento de promoção da saúde.

\section{Concluindo, no rumo da estratégia de educação permanente}

É neste cenário de múltiplas concepções e práticas que o nutricionista, por meio do PAE, pode encontrar a possibilidade de descobrir e/ou construir espaços nos quais suas ações sejam efetivamente educativas, estimulando práticas de alimentação saudável e transformando-se em verdadeiro agente de promoção da saúde.

Em seu cotidiano, o nutricionista que atua no PAE enfrenta a heterogeneidade de experiências sociais trazidas pelos grupos com os quais se relaciona, de diferentes níveis hierárquicos, e problemas os mais diversos na área de nutrição, o que exige visão mais crítica nas ações educativas. É importante lembrar que o estabelecimento da comunicação entre as partes está vinculado às relações institucionais estabelecidas, mas que, ao aceitarmos e compartilhar- 
A prática do nutricionista em escolas...

mos experiências e saberes do outro, estamos produzindo uma nova forma de condução do processo de aprendizagem, que pode gerar autonomia e transformações na prática profissional e nas concepções daqueles que participam da construção do processo. Essas ações justificam-se pela educação permanente, concepção introduzida no Brasil por Pierre Furter, nos idos dos anos 1960, e que atualmente é considerada uma estratégia do SUS para a formação e o desenvolvimento dos trabalhadores para o setor da saúde (BRASIL, 2004).

Entretanto, o que se verifica, algumas vezes, é a negação dessas práticas como campo de trabalho para profissionais de saúde, neste caso, nutricionistas, em oposição à supervalorização de ações de caráter normativo e fiscalizador. Está claro que não podemos subestimar a importância das ações técnicas, que tornam possível o oferecimento de refeições saudáveis em termos de nutrientes e condições sanitárias; porém, o que procuramos ressaltar é que, pela ampliação do leque de atribuições do nutricionista que atua no PAE, torna-se necessário repensar e redimensionar o peso que as ações educativas têm em sua rotina de trabalho. Elas não podem ser vistas como práticas pontuais, uma vez que, como já foi dito, a educação, aqui entendida como processo interativo, ocorre o tempo todo. Deseja-se que a divulgação de informações seja utilizada como meio de gerar autonomia nos indivíduos, tornando-os capazes de realizar escolhas de comportamentos saudáveis, entre eles hábitos alimentares. Especificamente no caso de outros profissionais envolvidos no PAE, o processo educativo precisa, antes de tudo, torná-los aptos a desempenhar suas funções de maneira autônoma e com capacidade de resolver os problemas que se apresentarem.

O conceito de educação permanente contraria a hipótese tradicionalmente aceita de que a vida possui duas fases distintas: uma, até a maturidade, na qual se aprende, e outra, na idade adulta, em que se utiliza o que foi aprendido (FURTER, 1976). Em uma sociedade que está mudando com rapidez incrível e impõe aos profissionais o desafio de adquirir, continuamente, novos conhecimentos, novas habilidades e atitudes necessárias para o desenvolvimento de suas atividades diárias, não seria possível conceber que esses profissionais sintam-se satisfeitos, por toda a vida laborativa, com os ensinamentos que aprenderam durante sua formação acadêmica. Ao contrário, o que se espera é que tenham a consciência da necessidade de continuar a aprender.

Com base nesta concepção, consideramos a necessidade de buscar espaços - entendidos como espaços físicos e sociais -, onde o nutricionista que atua no PAE possa, utilizando a prática como base para reflexão, problematizar concepções vigentes, propor estratégias que articulem os setores envolvidos no programa, e reformular práticas, quando necessário.

Ao analisarmos as falas das nutricionistas percebemos que, independente do tempo de formadas, muitas apresentam concepções educativas não críticas, em geral tradicionais, característica de uma formação baseada em um modelo biomédico, fragmentado e centrado na transmissão de conhecimentos (o que pode ser apontado como a primeira dificuldade que as profissionais encontram para desenvolver, em suas atividades cotidianas, um processo interativo de produção de conhecimento). Mas há, também, aquelas que entendem a saúde integrada a seus determinantes socioeconômicos, políticos e culturais, e que a adesão às proposições técnicas é influenciada pelas condições gerais de vida (dimensão coletiva) e não, apenas, pela validade científica. Este grupo, que se opõe à concepção tradicional, entende a educação como processo permanente baseado em troca de saberes.

No nosso entendimento, para produzir mudanças de práticas de saúde nos lugares 
onde essas práticas se fazem presentes, inclusive na escola, é necessário implementar ações educativas que aproximem especialistas e equipes de trabalho, baseadas em valores de natureza humanitária e de solidariedade, reconhecendo a saúde como direito de todas as pessoas. Nesse sentido, a formação profissional das nutricionistas precisa ser compreendida na perspectiva da educação permanente, havendo espaços para discutir o processo de trabalho, seus determinantes e a validade de resultados que possibilitem a transformação de práticas para melhores soluções dos problemas de saúde da população.

Com relação às práticas intersetoriais e interinstitucionais, verificamos que as nutricionistas percebem - e se preocupam com - a necessidade de estabelecer parcerias para melhorar e agilizar as ações destinadas à execução do PAE, tendo em vista sua dimensão de política pública. Embora preocupação quase unânime, não parece estar clara a forma como essas parcerias devem ser construídas. Em alguns casos, as relações estabelecidas são baseadas em atitudes unilaterais, nas quais as nutricionistas desejam sobrepor-se aos outros profissionais, muitas vezes desconsiderando seus saberes e aqueles oriundos da realidade local, práticas que podem ser identificadas como instrumentos de transmissão de regras de conduta. A este tipo de postura alia-se o receio de perder espaços de atuação, perante a divulgação de informações para outros profissionais envolvidos no PAE e para a comunidade, grupos que deveriam ser considerados parceiros no projeto de promoção da saúde. No que diz respeito especificamente à sociedade, vale ressaltar que a comunidade esclarecida e informada sobre seus direitos adquire maior controle sobre as decisões que afetam sua vida. Este é o sentido do termo empoderamento e, em conseqüência, do aumento de possibilidades para pressionar o Estado, exigindo condições universais de acesso à saúde.

Como ficou explicitado no estudo, torna-se urgente maior entrosamento entre as entidades que atuam no PAE, incluindo aquelas responsáveis pelo controle social, para que os papéis de cada uma sejam esclarecidos, anulando, ou reduzindo, as desconfianças mútuas e criando, assim, um ambiente propício ao diálogo.

Retomando os objetivos propostos no início do estudo, cremos ter deixado clara a importância de que a ação do nutricionista se dirija não só para a educação nutricional mas, também, para sua tomada de consciência da necessidade de estar em permanente processo de educação, entendendo as duas faces do mesmo processo: a do ensino e a da aprendizagem. As falas obtidas e analisadas confirmam o quanto ainda é necessário caminhar no rumo da educação permanente: aquele que nos mantém em constante desconforto, em crise, em dúvida, em persistente busca do novo. 
A prática do nutricionista em escolas...

\section{Referências}

ABBAGnANO, N. Dicionário de Filosofia. São Paulo: Martins Fontes, 2003.

AERTS, D.; ALVES, G. G.; LA SALVIA, M. W.; et al. Promoção de saúde: a convergência entre as propostas da vigilância da saúde e da escola cidadã. Cadernos de Saúde Pública, Rio de Janeiro, v. 20, n. 4, p. 1020-1028, 2004.

BRANT, R. V. PROMED: investigação sobre iniciativas de inovação curricular em escolas médicas públicas do Rio de Janeiro e de Minas Gerais. In: CONGRESSO MUNDIAL DE CIENCIAS DE LA EDUCACIÓN: EDUCADORES PARA UNA NUEVA CULTURA, 14., 2004, Santiago do Chile. Resumos... Santiago do Chile: 2004. p. 188. Disponível em: $<$ http://www.amcecongreso2004.cl>.

Planejar para desenvolver competência. Curso de Especialização em Educação a distância, Unidade 3, livro eletrônico, ISBN 3. 85-7458-038-4, Rio de Janeiro: SENAC/DN, 2002. p. 9. Disponível em <http://www.senac.br>

BRASIL. II Conferência Nacional de Segurança Alimentar e Nutricional. Relatório Final. Olinda (PE), 17 a 20 de março de 2004. Disponível em <https:/ /www.planalto.gov.br/ Consea/static/documentos/Outros/IIConferencia.pdf>. Acesso em 16 jun. 2005.

Ministério da Saúde. Portaria n $^{\circ}$ 198/GM, de 13 de fevereiro de 2004. Institui a Política Nacional de Educação Permanente como estratégia do Sistema Único de Saúde para a formação e o desenvolvimento de trabalhadores para o setor e dá outras providências. Brasília, 2004.

- Ministério da Saúde. Política Nacional de Alimentação e Nutrição. Brasília: Ministério da Saúde, 2003. (Série B. Textos Básicos de Saúde, 2. ed. rev.).

. MEC. Conselho Nacional de Educação, Câmara de Educação Superior. Resolução $\mathbf{n}^{\circ}$ 5, de 07/11/2001. Diretrizes Curriculares Nacionais do Curso de Graduação em Nutrição. Brasília, 2001.

Portaria $\mathrm{n}^{\circ} \mathbf{7 1 0}$, de 10 de junho de 1999. Aprova a Política Nacional de Alimentação e Nutrição. Brasília, 1999.

Presidência da República. Lei no 9.394 de 20 de dezembro de 1996. Estabelece as diretrizes e bases da educação nacional. Brasília, 1996.

Lei Orgânica da Saúde no 8.080, de 19 de setembro de 1990. Brasília, 1990.

. Ministério da Saúde. VIII Conferência Nacional de Saúde. Anais. s.l., Brasil.

Ministério da Saúde. Centro de Documentação, 1987. p. 129-32. 
CAMPOS, C. E. A. O desafio da integralidade segundo as perspectivas da vigilância da saúde e da saúde da família. Ciência e Saúde Coletiva, Rio de Janeiro, v. 8, n. 2, p. 569584, 2003.

CANINÉ, E. S. A prática do nutricionista em escolas municipais do Rio de Janeiro: um espaço-tempo educativo. Rio de Janeiro, 2005. Dissertação (Mestrado em Educação em Ciências e Saúde) - Universidade Federal do Rio de Janeiro.

COLARES, L. G. T. Processo de trabalho, saúde e qualidade de vida no trabalho em unidade de alimentação e nutrição: uma abordagem qualitativa. Rio de Janeiro, 2005. Tese (Doutorado) - Escola Nacional de Saúde Pública.

CORREIA, M. V. C. Que controle social? Os conselhos de saúde como instrumento. Rio de Janeiro: Fiocruz, 2000.

CZERESNIA, D. O conceito de saúde e a diferença entre prevenção e promoção. In: .; FREITAS, C. M. (Orgs.). Promoção da saúde: conceitos, reflexões e tendências. Rio de Janeiro: Fiocruz, 2003. p. 39-53.

DELUIZ, N. O modelo das competências profissionais no mundo do trabalho e na educação: implicações para o currículo. Boletim Técnico do SENAC, Rio de Janeiro: v. 27, n. 3, p. 12-25, 2001.

FILGUEIRAS, S. L.; DESLANDES, S. F. Avaliação das ações de aconselhamento: análise de uma perspectiva de prevenção centrada na pessoa. Cadernos de Saúde Pública, Rio de Janeiro, v. 15, sup. 2, p. 121-131, 1999.

FREIRE, P. Pedagogia do oprimido. 13. ed. Rio de Janeiro: Paz e Terra,1984.

FURTER, P. Educação e vida. 7. ed. São Paulo: Vozes, 1976.

GOMES, M. E. S.; BARBOSA, E. F. A técnica educativa de grupos focais para obtenção de dados qualitativos. Educativa. Instituto de Pesquisas e Inovações Educacionais, 1999. Disponível em: <www.dppg.cefetmg.br/mtp/Tecnica\%20de20Grupos\%20Focaisdoc>. Acesso em: 18 jan. 2005.

HABERMAS, J. Pensamento pós-metafísico: estudos filosóficos. Rio de Janeiro: Tempo Brasileiro, 1990. (Série Estudos Alemães)

INAD. Manual do programa de alimentação escolar: cardápios/escolas. Rio de Janeiro, 2005. (Mimeogr.)

Atribuições das coordenações do Instituto de Nutrição Annes Dias.

Documento interno. Rio de Janeiro, 2002. (Mimeogr.)

LEFEVRE, F.; LEFEVRE, A. M. C. Promoção de saúde: a negação da negação. Rio de Janeiro: Vieira e Lent., 2004. 
A prática do nutricionista em escolas...

LEITÃO, R. G. L. Não basta ouvir, é preciso escutar. Saúde em debate, n. 47, p. 46-49, 1995.

LIBÂNEO, J. C. Democratização da escola pública. São Paulo: Loyola, 1985.

MINAYO, M. C. S. O desafio do conhecimento: pesquisa qualitativa em educação. 7. ed. São Paulo/Rio de Janeiro: Hucitec/Abrasco, 2000.

MIZUKAMI, M. G. N. Ensino: as abordagens do processo. São Paulo: EPU, 1986.

OPAS. Organização Pan-Americana de Saúde. Disponível em: <www.opas.org.br/coletiva/ temas.cfm?id=17\&area=Conceito $>$. Acesso em: 04 fev. 2007.

POULAIN, J. P. Sociologias da alimentação: os comedores e o espaço social alimentar. Florianópolis: UFSC, 2004.

RAMOS, M. N. A pedagogia das competências e a psicologização das questões sociais. Boletim Técnico do SENAC, Rio de Janeiro, v. 27, n. 3, p. 27-35, 2001.

SANTOS, B. S. Introdução a uma ciência pós-moderna. Rio de Janeiro: Graal, 1989.

SCHALL, V.; STRUCHINER, M. Educação no contexto de HIV/AIDS: teorias e tendências pedagógicas. In: CZERESNIA, D.; SANTOS, E. M.; BARBOSA, R. H. S; et al. (Orgs.). AIDS: pesquisa social e educação. São Paulo: Hucitec/Abrasco, 1995. p. 84-105.

SMS-RJ. Decreto 13.795, de 03/04/1995. Transfere o Instituto de Nutrição Annes Dias para Secretaria Municipal de Saúde e dá outras providências. Rio de Janeiro, 1995.

STRUCHINER, M.; REZENDE, F.; RICCIARDI, R. M. V.; et al. Elementos fundamentais para o desenvolvimento de ambientes construtivistas de aprendizagem à distância. Revista Tecnologia Educacional, v. 26, n. 142, p. 3-11, 1998.

SUANNO, M. V. R. Auto-avaliação institucional: princípios e metodologia do grupo focal. In: BELLO, J. L. P. (Org.). Pedagogia em foco. Rio de Janeiro. Disponível em: < http:// www. pedagogiaemfoco.pro.br >. Acesso em: 20 set. 2001.

Em busca de uma educação nutricional crítica. In: VALENTE, F. L.S. (Org.).

Fome e desnutrição: determinantes sociais. São Paulo: Cortez, 1989. p. 66-94.

VALLA, V. V. Controle social ou controle público? Uma contribuição ao debate sobre controle social. In: WENDHAUSEN, A. (Org.). O duplo sentido do controle social: (des)caminhos da participação em saúde. Itajaí: UNIVALI, 2002. prefácio.

VALENTE, F. L. S. (Org.). Direito humano à alimentação: desafios e conquistas. São Paulo: Cortez, 2002. 
Caniné, E. S.; Ribeiro, V. M. B.

WHO. WORLD HEALTH ORGANIZATION. Ottawa Charter for Health Promotion. First International Conference on Health Promotion, Ottawa, 21 November 1986, WHO/ HPR/HEP/95.1. Disponível em < http://www.who.int/hpr/NPH/docs/ottawa_charter_ hp.pdf>. Acesso em: 03 jul. 2004.

. Medical educacion in the United States and Canada by Abrahan Flexner. Bulletin of the World Health Organization, v. 80, n. 7, 2002.

WIGLEY, M. A desconstrução do espaço. In: SCHNITMAN, D. F. (Org.). Novos paradigmas, culturas e subjetividade. Porto Alegre: Artes Médicas, 1996.

ZARAFIAN, P. E1 modelo de competencia y los sistemas productivos. Montevideo: Cinterfor, 1999.

Artigo recebido em outubro de 2006 e aceito em março de 2007. 